PRESIDENTIAL ADDRESS: XVIII Canadian Congress of Neurological Sciences

\title{
The Neurologist as Educator
}

\author{
T.J. Murray, President, Canadian Neurological Society
}

Neurologists have had a long tradition of commitment and excellence in education. Whether we see our major role in clinical practice or clinical investigation, whether we are based in the community or in a university, virtually all of us have a role as teachers, a role in which we take great pride.

We have all had our own experiences with great teachers those who had a strong personal influence in our education. Education, after all, is what is left when we have forgotten what we have learned. If you think about it, the teachers who influenced you in your past were probably those who stimulated your interest in a subject, opened your eyes to a new way of looking at things, or provided support and attention at a developing point in your career. It is ironic then that so much time and effort is devoted to crowding facts and information into teaching when it is other aspects of teaching that have lasting value.

It has often been noted cynically that we spend fifteen to twenty years acquiring clinical skills but sometimes less than fifteen to twenty minutes in formal training for our role as teachers. Perhaps this suggests that excellence in teaching is not as valued by the university as excellence in research or administration. While some may clamor for more university staff appointments to be made on the basis of excellence in teaching, stronger demands are made for research skills, with teaching ability taken for granted. Teachers complain that the rewards in university go to those successful in research and publication but not to those who teach well.

What characteristics make a teacher effective? Students indicate that their learning is facilitated by teachers who encourage student participation, have positive attitudes towards teaching, emphasize student centered problem solving, have a humanistic orientation, and incorporate references and research results in their teaching. The personal qualities of teachers rated as effective were the following: They were gregarious, adventurous, frivolous, had abundant emotional response, strong artistic and sentimental interests, more interest in the opposite sex, and were polished, fastidious and cool. (Simpson 1972). The qualities that lead a physician to be designated as a poor or ineffective teacher are not different qualities, but rather a lack of the positive characteristics of a good teacher.

Neurologists often have reputations as good teachers, partly because of the nature of those who select a field such as neurology, and also because of the nature of the subject, which is diverse, interesting, dramatic and because the brain is central to everyone's concept of themselves and their existence.

\section{Undergraduate Medical Students}

After graduation from medical school I spent a few years in family practice. I became aware that excellent teaching in a traditional medical school curriculum did not equip me to assess or manage the common and important neurological cases seen in a busy practice. Later, as a neurologist, I began a series of studies of 25 family physicians and their experience and problems with neurology in their practices. (Murray, 1976: Murray, 1977). Despite our teaching, practicing physicians felt insecure about managing patients with neurological diseases. Their greatest difficulties were, first, identifying that the patient had a neurological problem and second, carrying out the neurological examination. They had not acquired the basic skills that allowed them to assess the patient confidently, and did not know how to interpret the signs even when they were able to elicit them. This level of difficulty did not result in the problems merely being referred; often the patients were simply ignored.

After an evaluation of the patient problems seen in family practice, and an assessment of neurological problems according to frequency, seriousness and treatability of the condition, it was possible to suggest an outline for reevaluating the curriculum. Once students have developed an effective, efficient method of examining the nervous system, they should learn about neurological disorders that are important in practice. A brief outline is presented in Table 1.

Why do students feel so negative and insecure about the nervous system and patients with neurological disorders? Perhaps it is due in part to the complexity of the anatomy and physiology of the nervous system. But perhaps we turn students off the nervous system by initially giving them too much basic science detail, for the most part separated from clinical problems. Medical students will develop a negative attitude towards the nervous system if we introduce them to basic neurosciences in a cold isolated fashion. Often they are inundated with basic science information in a fashion that seems irrelevant to medicine and the objectives for which they entered medical school. Neuroanatomy, neurophysiology and neurochemistry become obstacles to be hurdled before the students can get to see patients, confront real problems, and start acting like doctors. I believe that the correct approach is something akin to the McMaster method of presenting clinical problems which stimulate the student to delve in depth into all of the areas of anatomy, physiology, biochemistry and clinical medicine to understand what is going on. In that situation we have the greatest positive force in learning - the excitement and motivation of the student.

This heavy introduction to the nervous system creates a feeling of negativism that most students never lose. Later they develop a different feeling of negativism because they are only exposed to the small percentage of seriously ill and therapeutically resistent neurological patients who become hospitalized. Furthermore, neurologists confuse students by the tremendous jumps in deductive reasoning that they make in problem solving. This fascinates but creates the impression amongst students 
Table 1:

NEUROLOGICAL CONDITIONS

REQUIRING EMERGENCY MANAGEMENT

Coma (including the initial management of the unconscious patient and a rational approach to identifying the likely etiology and specific therapy)

Meningitis

Status epilepticus

Acute visual failure

Any rapidly progressive neurological deficit

CNS trauma

NEUROLOGICAL CONDITIONS WHICH ARE COMMON Headaches Dizziness and vertigo Alterations in consciousness

Weakness

Seizures

Pain syndromes

Strokes

Peripheral

Parkinson's disease neuropathies

Multiple sclerosis

Mental retardation

Dementia

NEUROLOGICAL DISORDERS OF IMPORTANCE BECAUSE THEY ARE TREATABLE, AND BECAUSE EMPHASIS OF TREATABLE NEUROLOGICAL DISEASE FOSTERS A POSITIVE APPROACH TO NEUROLOGY

Seizures

Transient ischemic Trigeminal neuralgia attacks

Subdural hematoma Migraine

Temporal arteritis Myasthenia gravis Wilson's disease

Parkinson's disease Polymyositis Meningitis

NEUROLOGICAL DISORDERS OF IMPORTANCE OR

INTEREST BECAUSE THEY AID UNDERSTANDING OF THE NERVOUS SYSTEM

Disorders of memory Sleep Disorders

OR BECAUSE OF IMPORTANCE IN ILLUSTRATING NEW DEVELOPMENTS IN THE NEUROSCIENCES

Slow virus infections Herpes simplex encephalitis

that such neurological wizardry is something they can never master.

Learning has three stages: (1) romance, (2) precision; and (3) generalization. At an early stage of undergraduate learning neurologists have a unique opportunity to excite the students with the romance of understanding the brain and how it functions and malfunctions. But we often waste the opportunity when medical students are first exposed to the nervous system by overwhelming them with precision and facts, and later dazzling them with complex pathways, inductive jumps in problem solving and sleight of hand examination skills. When I studied the problems that family physicians had in handling neurological problems it was clear they had learned that the nervous system was a complex black box only capable of being understood by a neurologist, and the neurological exam was not something they could be expected to master or employ effectively in problem solving.

At the First Workshop on Neurological Education at McMaster University (Barrows and Smith 1974) it was suggested that all the important basic science concepts could be learned if the student were asked to solve thirteen clinical problems (Table 2). Given adequate time the student would search out the knowledge required to understand and solve these problems. Basic scientists however are justifiably nervous about this format. Clinicians have a tendency to dominate combined teaching sessions which are rarely successful. More thought is needed to develop a program that stimulates the student to learn the important concepts, skills and approaches to the patient with neurological disorders, and do so with a positive attitude.

Table 2: Neurological Problems for Teaching Basic Science

Headache

Vertigo

Dementia

Encephalopathy

Movement disorders

Pain syndromes

Anatomical localization problems

Muscle wasting

Aphasia

Epilepsy

Paresthesiae

Coma

Polyneuritis

\section{Training of Neurology Residents}

Twenty-five years ago the training of a Canadian neurologist was quite varied and determined to a great extent by the desires of the trainee. Thus a trainee might get his medical and initial clinical neurology experience in Canada, and then spend a year or two at Queen Square or at a major center in the United States. The need for national standards in training programs was recognized and the Royal College led the way in establishing minimal standards for training that became accepted across the land. Although this has produced a remarkable improvement in all programs, it has resulted in a rather stereotyped approach to resident training. I look with some concern to the increasing tendency of our trainees to stay in one program, taking identical rotations, with the years of study and experience determined, not by the exciting opportunities available, but by the specter of the Royal College examinations.

It does not matter what we say the aim of our training of residents may be if we have a single objective at the end of that training period: The Royal College Examinations. We may wish our residents to be well educated, well rounded, humanistic individuals with many other attributes, but they quickly realize that the objective of the training program is to pass the examinations at the end, and all of their energy is dedicated to that. Our in-training evaluations have to be clearly related to those attributes which we feel are important if we wish to foster other objectives in our trainees.

In the past most neurologists practiced in larger centres, usually in association with a medical school. Increasingly we are now seeing the rise of the community neurologist whose major objective is to provide excellent patient care and consultation (Simpson 1977). Should the training be different for the community neurologist? Should all residents demonstrate a high level of excellence in an academic setting from whence they go their separate ways, or should the training reflect their career plans. Should the training of a resident aiming for a career in investigative medicine be different? 
What should the training be for a clinical investigator? Given the increasing pressures and insecurities for clinical researchers, we cannot continue to rely on individuals to just add on two or three years of research training after clinical training. The basic science year should be a research year for these individuals and a post fellowship research experience should flow directly from that. The growing body of $\mathrm{PhD}$ researchers will not replace a clinical neurologist who can examine and address clinical questions clearly and who has the research skills and training to design methods for answering these questions. Our training programs must be redesigned for the development of clinical researchers, or the number of neurologists who plan a lifetime career in research will diminish. Only some programs will have the resources to offer such experience and training for clinical research.

Donald Baxter in his stimulating Richardson Address on "Prospects for Canadian Medical Neurology" (Baxter 1975) suggested that trainees should have a broader background in internal medicine, and have greater experience in clinical neurology, and investigative techniques, finally choosing careers as clinicians, physician scientists or neuroscientists. He added that it was unlikely that all training programs would be able to meet all these goals. I believe we must allow some flexibility within our training programs for the unusual but innovative and creative individual.

But why are we training these young men and women? Where are they going to go, and how many will we need in another five years? We have disturbingly little hard information about specific manpower requirements and future trends, and it has been mostly because we have not made the effort to accumulate the hard data and make the firm decisions that are required. It is apparent to me that governments will make the kind of decisions about the practice of Neurology that we are reluctant to face, and they will do it with their aims in mind, aims which are perhaps more related to economic restraint than to improved neurological care.

How many neurologists are needed? Our manpower study under Dr. Silversides suggested one per 90,000 population, later altered to one per 100,000 . We then look with some surprise to the Americans who are aiming for one per 25,000. The British on the other hand would look surprised at our figure, because they have roughly one neurologist per 250,000 population. I don't think the answer is in arguing about whose figure is correct. It is more important to determine the pattern of practice that gives rise to the varying figures in different countries, and to determine what the appropriate figure is for that country.

Our training programs in Canada have been consistently turning out twenty to twenty-five neurologists per year. We have been catching up to the needs in this country for neurologists, and despite recognizing some specific areas of regional need, we are beginning to see the problems of overproduction of specialists in some areas. It will be a long time before our graduate trainees find it difficult to make a living, but it is interesting that $50 \%$ of the American neurologists now feel that they have too many neurologists, and there is some pressure to try to limit the number going out into the community. Increasing the number of neurologists also alters the pattern and profile of neurological practice as more and more minor problems are referred because the increased service is available.

We must recognize that Canada cannot continue to absorb twenty to twenty-five neurologists per year over the next decade, particularly when the average age of a neurologist is about 38 , and we will not be seeing a proportional number of people leaving practice for many years.

To have a rational approach to the manpower question, we may have to consider discontinuing some of the small training programs in Canada that have never been able to train a significant number of neurologists, and have not been able to attract a consistent number of high level Canadian trainees or provide the experiences outlined by Baxter. This will leave a number of other programs to generate trainees for these areas. Some rethinking of government policies will be required so that the very insular and provincial attitudes towards allocating training posts do not prevail. Provinces have tended to support the specialists needs for their province only, and we have to see a reawakening of the concept of a national pool.

We will see a number of conflicting pressures over the next few years which will take time to settle out. Communities, hospitals and physician groups will continue to seek more consultant neurologists. Universities at the same time will have decreasing resources to hire full time neurologists. University divisions and departments will have increasing needs for clinical neurologists to generate funds to support departmental and often university activities. At a time when there is a need for career investigators in neurology, the rewards and security of clinical practice will draw away many potential candidates early in their training. There will be pressures to maintain smaller and sometimes weaker programs because of local manpower needs and local pride, and increasing pressure to cut the larger programs because they are in areas with few manpower needs.

Who will make the important but hard decisions? We must, as a specialty group. It might be suggested that the Royal College should make such judgments, but this would never happen. The College evaluates the standards of training programs and will not rule on questions such as national manpower needs. It we neglect our rightful role in deciding the future directions of neurology, governments will have no hesitation in doing so and we will continue to try to respond after the fact.

\section{Training of Other Specialists}

A knowledge of neurology is important in the specialties of internal medicine, psychiatry, physical medicine and rehabilitation, and neurosurgery. Unfortunately, many trainees in these specialties do not spend any time on a neurology service. In Canada most residents in internal medicine spend at least one rotation on neurology during their training, but this is not mandatory. In many schools up to $30 \%$ of the trainees in internal medicine do not rotate on an organized neurology service. This greatly concerns me because I see an increasing separation of neurology and internal medicine which I think may be detrimental to both. I do believe that neurology has a special status within internal medicine but it is still a medical specialty, and our approach and concepts of patient care and problem solving are still those of medicine.

Also of concern is the fact that residents can enter a neurology program with only one year of straight internship in internal medicine. On the other hand internists seem to be neglecting the nervous system in their approach to their specialty. Internal medicine appears to be developing into a specialty of medical diseases from the neck down. For instance, the numerous and 
extensive continuing medical education courses offered by the American College of Physicians rarely are devoted to the nervous system.

An internist should know neurology. In a community practice a large number of the patients he or she will be asked to see in consultation will have neurological disease, particularly if there is no neurologist in that community. $30 \%$ of the patients in a general medical hospital have a significant neurological complaint, $10 \%$ of the patients in a general medical hospital are there because of a primary neurological problem.

We should recognize that the general medicine resident has specific educational needs on a neurology service. We should seek out ways to make the experience appropriate and not just treat him as another neurology resident.

Likewise, the psychiatrist has increasing needs to understand and deal with neurological problems and "borderline" syndromes. It has been said that psychiatry is just neurology without signs, and increasingly we are finding that traditional psychiatry is coming into the neurological sphere as we learn more about the basic biochemistry and neurotransmitter abnormalities in psychiatric disease. Again, the experience in neurology should be relevant for the resident in psychiatry. To encourage the development of this kind of educational relationship between the two departments, some more flexible arrangements will be required.

\section{Continuing Medical Education}

I have come to the realization that I was somewhat naive in my approach to continuing medical education a number of years ago. When I completed the studies of family practitioners and evolved some concepts of physician training and continuing medical education, I felt that if we trained family physicians to recognize and handle the common neurological problems that this would provide a lot of the unmet neurological care. It would also have these patients managed by their own physicians in their own community rather than referring the majority of them to a major center for specialist consultation. This was quite erroneous, however, as we have consistently found that continuing medical education for general physicians increases the number of consultations. It seems primarily to enable the physician to recognize important neurological problems, which are then referred, often to the person who gave the continuing medical education teaching. I am not sure that is all wrong, but we must be clearer in stating our CME goals, and recognize the effects of this type of teaching.

\section{Education of Health Professionals}

Continuing education is now an important part of the programs in nursing, physiotherapy, occupational therapy, and other allied health professions. The neurologist is frequently asked to give educational programs for these groups. Teaching in dentistry, outpost nursing, pharmacy, physiotherapy, occupational therapy and numerous nursing groups is now occupying an increasing proportion of the time of our neurology group. It is interesting that we now spend more time giving courses and lectures to allied health professions than we do to undergraduate medical students. Some neurologists feel that that is an inappropriate use of neurologist's time, and that the education of these groups should be done by individuals within their profession. Others feel that the best person to instruct on neurological conditions and problems is the neurologist. It is an important question because the demands for our time from these groups will be increasing.

Personally I feel that neurologists are the appropriate ones to teach neurological assessment and neurological problems and we should not pass up this important opportunity to communicate the knowledge we have about patient management to other professionals who also care for patients with neurological disorders.

\section{Education of the Public}

In recent years there has been a lot of criticism that physicians and medical scientists have their own private club. We have been quite willing to request and demand increasing funds for research from the public. and through their tax dollars, from the government, but we are often reluctant to discuss with the public the research to be carried out and the implications for society. There has been a feeling that it is improper and impure for medical scientists to use a public forum to discuss their research. I don't think that can be justified. The public has a right to demand explanation of medical science if they are to be asked to fund it.

Physicians harbour a phobia about being misquoted, about having their research trivialized, sensationalized and bastardized by the media. We have long criticized articles prepared by reporters without the advantage of expert discussion. It should be our responsibility to provide them with the necessary background and information to understand advances in medicine. Public education can be well done through talks and discussions with lay groups in the community. This assists community groups who are supporting research and also helps clarify for the public problems and issues related to our profession.

\section{Education of the Patient}

Henry Miller pointed out that one of the central problems in medical education has been "the difficulties of combining education in scientific biology with the cultivation of the personal and human qualities implicit in the doctor-patient relationship".

In a previous paternalistic medical era, education of the patient was not thought to be overly important. With the recognition by patients that they are responsible for their own health, the physician is increasingly regarded as an advisor in the process of self-management. Physicians have been late in recognizing this and there still remains a strong flavor of paternalism among physicians. We must remember that the patients' disease is their problem and it is ultimately their responsibility. It is not an interesting syndrome belonging to the physician for him to deal with in any fashion he sees fit. I am sure we would all reject the idea that keeping patients in the dark is good for them, particularly in areas such as epilepsy, Parkinsons's disease, migraine and transient cerebral ischemic attacks, where the decisions, actions and management depend to a great extent on the patient's understanding and compliance.

It is an interesting paradox that while medicine is becoming more technical, subspecialized, disease oriented and impersonal, the patient is asking the physician to act as an educator and 
advisor, with wisdom in areas such as birth control, drug use, euthanasia, exercise, social issues, stress, disorder of life style. sex, divorce, behavioral disturbances, patient rights, nutrition, and death.

\section{Conclusions}

Neurologists have long been noted for their skills as educators. Neurology lends itself to dramatic demonstrations in the classroom, at the bedside and in the clinics. That very dramatic and interesting aspect of clinical neurology has led to an increasing fascination about our field by others, but it has also often bewildered students and colleagues who came away from the experience with the feeling that, interesting as the whole show was, it demonstrated a knowledge of neuroscience and an expertise and proficiency that they could probably never achieve.

I would suggest that we have to examine carefully our approach to teaching basic neurological skills to undergraduate medical students and non-neurological physicians. We should concentrate on the basic skills required to identify, assess and manage neurological conditions that are common. treatable, or require emergency management. In the education of these students we must defuse some of the mythology of neurology that suggests neurological patients are difficult and complex problems accessible only to the highly trained intellectual. To manage the problems that they will see. these physicians must feel secure in their ability to meet and deal with these problems at an appropriate level.

The training in neurology of non-neurological physicians, such as general internists. psychiatrists. physiatrists and neurosurgeons must be made more flexible and tailored for their special needs.

I think we have to give further consideration in our educational programs and philosophies, to the increasing needs in areas that have not received much attention in the past. These include psychosocial problems, ethics, geriatrics, intensive care and chronic disability.

In the training of neurological specialists we are going to have to consider the required steps when we meet most of the manpower requirements. We need strategies for increasing the numbers of neurologists in the Prairies and the Maritimes. with some limitation of the large numbers of the neurologists that have been entering practice in British Columbia, Ontario and Quebec. We will have to consider discontinuing some borderline programs that do not meet the requirement for excellence or for manpower needs.

To be a teacher in medicine is a wonderful privilege. It does require that we constantly strive to improve our abilities, and constantly reassess our methods and concepts so that our students learn, and continue to learn that which is necessary and important. And in this process we must constantly remember it is not what we teach that is important, but what our students learn.

I thank you for the honor of acting as President of the Canadian Neurological Society and President of the Congress of Neurological Sciences. The Congress is a unique organization of neurologists, neurosurgeons, child neurologists and clinical neurophysiologists that allows a sharing of knowledge, experience and fellowship that we must preserve and foster.

\section{REFERENCES}

Barrows, H.S. and Smith, D. (1974). The Neurological Education Workshop. McMaster University Press.

Baxter, D.W. (1975). Prospects for Canadian Medical Neurology. Can. J. Neurol. Sci., pp. 101-107.

Murray, T.J. (1976). Concepts of Undergraduate Neurological Teaching. Clin. Neurol. Neurosurg., 79-4, pp. 273-284.

Murray, T.J. (1977). Relevance in Undergraduate Neurological Teaching. Can. J. Neurol. Sci.. 4:131-137.

Simpson, C.A. (1977). A Community Neurologists' Personal Viewpoint on Neurological Training. Can. J. Neurol. Sci. 4:265-268.

Simpson, M.A. (1972). Desirable Attributes for a Teacher. Medical Eduation ... A Clinical Approach. pp. 90-93. 